\title{
Flavanol metabolites distribute in visceral adipose depots after a long-term intake of grape seed proanthocyanidin extract in rats
}

\author{
Aida Serra ${ }^{1}$, Cinta Bladé ${ }^{2}$, Lluís Arola ${ }^{2}$, Alba Macià $^{1}$ and Maria-José Motilva ${ }^{1 *}$ \\ ${ }^{1}$ Department of Food Technology, XaRTA-UTPV, Escola Tècnica Superior d'Enginyeria Agrària, \\ Universitat de Lleida, Avda/Alcalde Rovira Roure 191, 25198 Lleida, Spain \\ ${ }^{2}$ Department of Biochemistry and Biotechnology, Universitat Rovira $i$ Virgili, Campus Sescel.lades $s / n$, \\ 43007 Tarragona, Spain \\ (Submitted 9 August 2012 - Final revision received 4 February 2013 - Accepted 4 February 2013 - First published online 14 March 2013)
}

\begin{abstract}
A considerable number of epidemiological investigations and intervention studies have supported an association between the intake of flavanol- and proanthocyanidin-containing foods and a decreased risk of metabolic diseases. Nonetheless, less is know about the capacity of tissues to accumulate flavanols and/or their metabolites. The main objective of the present study was to determine ( $n$ 20) plasma bioavailability and disposition in the liver, muscle, brown adipose tissue (BAT) and white adipose tissues (mesenteric and perirenal) in rats after a long-term consumption of three doses of grape seed phenolic extract $(5,25$ and $50 \mathrm{mg} / \mathrm{kg}$ body weight) for $21 \mathrm{~d}$ in order to determine whether there is a dose-response relationship. Glucuronidated conjugates (total glucuronidated conjugates: $\mathrm{C}_{5} \mathrm{mg} / \mathrm{kg} 1.9 ; \mathrm{C}_{25} \mathrm{mg} / \mathrm{kg}$ 6.4; $\mathrm{C}_{50 \mathrm{mg} / \mathrm{kg}} 27 \cdot 7 \mu \mathrm{mol} / 1$ plasma) followed by methyl glucuronidated conjugates (total methyl glucuronidated conjugates: $\mathrm{C}_{5} \mathrm{mg} / \mathrm{kg} 1.98$; $\mathrm{C}_{25} \mathrm{mg} / \mathrm{kg} 4.48 ; \mathrm{C}_{50 \mathrm{mg} / \mathrm{kg}} 12.5 \mu \mathrm{mol} / \mathrm{l}$ plasma) were the main flavanol metabolites quantified in plasma, also detecting a dimer in its free form $\left(\mathrm{C}_{25} \mathrm{mg} / \mathrm{kg} 0 \cdot 74 ; \mathrm{C}_{50} \mathrm{mg} / \mathrm{kg} 0.79 \mu \mathrm{mol} / 1\right.$ plasma). Each of the studied organs has a particular behaviour of accumulation and response to the assayed grape seed extract doses, with an exponential bioavailability-dose relationship in BAT, in which flavanols could play an important role in the reduction or prevention of obesity, modulating the functionality of that tissue.
\end{abstract}

\section{Key words: Flavanols: Long-term intake: Tissue distribution: Adipose tissue}

Flavan-3-ol and proanthocyanidins are the most abundant flavonoid subgroups in the human diet ${ }^{(1)}$, with a total flavonoid intake of $313 \mathrm{mg} / \mathrm{d}$ for the Spanish population (proanthocyanidins: $189 \mathrm{mg} / \mathrm{d}$; flavonoids without proanthocyanidins: $124 \mathrm{mg} / \mathrm{d}$ ), where proanthocyanidins represent $60 \%$ of the total phenolic intake ${ }^{(2)}$. These compounds are mainly found in apples, legumes, grapes, nuts, red wine, tea and cocoa $^{(3)}$. Epidemiological research and intervention studies have supported an association between the intake of foods containing flavanol and proanthocyanidin and a decreased risk of diseases, in particular $\mathrm{CVD}^{(4-6)}$ and cancer $^{(7)}$. Moreover, the consumption of flavanol- and proanthocyanidin-rich foods improves dyslipidaemia ${ }^{(8,9)}$, insulin sensitivity ${ }^{(10)}$ and obesity ${ }^{(11)}$ in humans.

Grape seed proanthocyanidin extract (GSPE) improves the atherosclerotic risk index and reduces postprandial triacylglycerolaemia, in both healthy ${ }^{(12,13)}$ and dyslipidaemic rats ${ }^{(14)}$. Moreover, GSPE improves glycaemia in rats with altered glucose homeostasis ${ }^{(15,16)}$. In addition, GSPE modulates mitochondrial function, increasing their oxidative capacity in the muscle, white adipose tissue (WAT) and brown adipose tissue (BAT) of rats ${ }^{(17)}$. The action of the bioactive compounds contained in GSPE could be linked to the modulation of signalling pathways, as occurs with the activation of the insulin receptor and key targets of insulin signalling pathways $^{(18)}$. Moreover, the hypolipidaemic action of GSPE is mediated by the nuclear receptors farnesoid-X-receptor and small heterodimer partner, a signalling pathway leading to lowered lipogenesis and secretion of VLDL in the liver, as demonstrated in previous experiments ${ }^{(19,20)}$

Over recent years, great effort has been made to determine flavanol and proanthocyanidin bioavailability with a low grade of polymerisation, confirming dimer and trimer absorption ${ }^{(21-24)}$. Furthermore, plasma kinetics of parental molecules and metabolites have been defined ${ }^{(25,26)}$. However, less is known about the capacity of organs to accumulate flavanols and/or their metabolites. Previous experiments have demonstrated the tissue distribution of flavanol

Abbreviations: BAT, brown adipose tissue; GSPE, grape seed proanthocyanidin extract; LOD, limit of detection; LOQ, limit of quantification; WAT, white adipose tissue.

*Corresponding author: Dr M.-J. Motilva, fax +34973 702596, email motilva@tecal.udl.es 
metabolites practically throughout the body, even crossing the blood-brain barrier, after an acute intake of a flavanolrich extract ${ }^{(27)}$, and a similar profile of tissue disposition was detected after an acute intake of a dietary dose of flavanols and proanthocyanidins with a low grade of polymerisation, using cocoa cream as a source of polyphenols ${ }^{(28)}$. Flavanol metabolites and phenolic acids have been detected at nanomolar levels in tissues, such as the heart, lung and liver. However, information derived from an acute intake experiment is not sufficient to evaluate correctly the tissue distribution of flavanols and proanthocyanidins with a low grade of polymerisation and/or their metabolites in tissues.

To gain insight into the molecular mechanisms used by flavonoids to modify lipid, glucose and energy metabolism, it is essential to determine which flavanol and/or metabolite reaches and accumulates in the liver and adipose tissues. As mentioned above, the concentrations of flavonoid metabolites in organs have been measured with acute and high doses of flavanols $(27,28)$. Thus, the aim of the present study was to determine flavanol metabolites in rat liver, muscle and adipose tissues after a long-term consumption of lower doses of GSPE than previously studied, this being a situation closer to that of the real human consumption of proanthocyanidins. The experiment was performed with three doses of GSPE $(5,25$ or $50 \mathrm{mg} / \mathrm{kg}$ body weight) for $21 \mathrm{~d}$ in order to determine whether there is a dose-response metabolite distribution in the liver, muscle, WAT (mesenteric and perirenal) and BAT.

\section{Materials and methods}

\section{Chemicals and reagents}

GSPE was kindly provided by Les Dérives Résiniques et Terpéniques. This proanthocyanidin extract contained monomers ( $58 \mu \mathrm{mol}$ catechin/g extract, $52 \mu \mathrm{mol}$ epicatechin/g extract, $5.5 \mu \mathrm{mol}$ epigallocatechin/g extract, $89 \mu \mathrm{mol}$ epicatechin gallate/g extract, $1.4 \mu \mathrm{mol}$ epigallocatechin gallate/g extract), dimers $(250 \mu \mathrm{mol} / \mathrm{g}$ extract), trimers $(1568 \mu \mathrm{mol} / \mathrm{g}$ extract), tetramers $(8.8 \mu \mathrm{mol} / \mathrm{g}$ extract $)$, pentamers $(0.73 \mu \mathrm{mol} / \mathrm{g}$ extract) and hexamers $(0 \cdot 38 \mu \mathrm{mol} / \mathrm{g}$ extract $)$.

The internal standard catechol, and the standards of $(-)$-epicatechin, (+)-catechin, (-)-epigallocatechin and (-)-epigallocatechin-3-O-gallate were purchased from Sigma Aldrich and proanthocyanidin dimer B2 (epicatechin-(4ß-8)epicatechin) from Fluka Company. Acetonitrile (HPLC grade), methanol (HPLC grade), acetone (HPLC grade) and glacial acetic acid ( $\geq 99 \cdot 8 \%)$ were of analytical grade (Scharlab). Ortho-phosphoric acid (85\%) was purchased from MontPlet \& Esteban S. A. Formic acid and L- $(+)$-ascorbic acid (reagent grade) were all provided by Scharlau Chemie. Ultrapure water was obtained from a Milli-Q water purification system (Millipore Corporation).

\section{Treatment of animals and plasma and tissue collection}

A total of twenty male Wistar rats (5-6 weeks) weighing 150-175 g were purchased from Charles River. The animals were housed in animal quarters at $22^{\circ} \mathrm{C}$ with a $12 \mathrm{~h}$ light $-12 \mathrm{~h}$ dark cycle (lights on from 08.00 to 20.00 hours) and were fed ad libitum with a standard chow diet (Panlab) and tap water. After 1 week of adaptation, the animals were trained to lick condensed milk ( $1 \mathrm{ml})$, which was used as a vehicle for administering GSPE, for an additional week. After this period, the animals were randomly divided into four groups ( $n 5$ each group), including the control group. Each group was treated with 5 , 25 or $50 \mathrm{mg} \mathrm{GSPE} / \mathrm{kg}$ body weight per d dispersed in condensed milk. The control group was treated with condensed milk. GSPE was administered every day at 09.00 hours for $21 \mathrm{~d}$. On day 21 , $5 \mathrm{~h}$ after the GSPE treatment, rats were anaesthetised with ketamine/xylazine and killed by exsanguination from the abdominal aorta using syringes, with heparin as the anticoagulant. Plasma was obtained by centrifugation and stored at $-80^{\circ} \mathrm{C}$ until analysis. Liver, muscle, BAT and mesenteric and perirenal WAT were excised and frozen immediately in liquid $\mathrm{N}_{2}$ and stored at $-80^{\circ} \mathrm{C}$ until the analysis of phenolic metabolites. All experimental procedures were performed according to the current national and institutional guidelines for animal care and in place at Universitat Rovira i Virgili (Spain). The Animal Ethics Committee of the Universitat Rovira i Virgili approved all the procedures.

\section{Extraction of flavanols and proanthocyanidins with a low grade of polymerisation from plasma and tissues}

The method used to extract flavanols and proanthocyanidins with a low grade of polymerisation and their metabolites from plasma and tissues was based on the methodologies described in our previous papers ${ }^{(29,30)}$. In order to clean up the biological matrix and to preconcentrate the phenolic compounds, plasma samples were pretreated by microelution solid-phase extraction, and rat tissue samples were pretreated by a combination of liquid-solid extraction and microelution solid-phase extraction. Briefly, the extraction was done with $60 \mathrm{mg}$ of freeze-dried tissue to which $50 \mu \mathrm{l}$ of ascorbic acid (1\%), $50 \mu \mathrm{l}$ of catechol (20 mg/l, dissolved in $4 \%$ phosphoric acid) as an internal standard and $100 \mu \mathrm{l}$ of phosphoric acid (4\%) were added. The sample was extracted four times with $400 \mu \mathrm{l}$ of $4 \%$ watermethanol-phosphoric acid (94:4:1, by vol.). Then, $400 \mu \mathrm{l}$ of the extraction solution were added to each extraction. The sample was sonicated during $30 \mathrm{~s}$, maintained in a freeze water-bath to avoid heating and then centrifuged for $15 \mathrm{~min}$ at $14000 \mathrm{rpm}, 20^{\circ} \mathrm{C}$. The supernatants were collected, and then the extracts were treated by microelution solid-phase extraction before the chromatographic analysis of flavanols and proanthocyanidins with a low grade of polymerisation and their metabolites. OASIS HLB $\mu$ Elution Plates ( $30 \mu \mathrm{m}$; Waters) were used. Briefly, these were conditioned sequentially with $250 \mu \mathrm{l}$ of methanol and $250 \mu \mathrm{l}$ of $0 \cdot 2 \%$ acetic acid. Then, $350 \mu \mathrm{l}$ of $4 \%$ phosphoric acid were added to $350 \mu$ of the tissue extract or plasma, and then this mixture was loaded onto the plate. The loaded plates were washed with $200 \mu \mathrm{l}$ of Milli-Q water and $200 \mu \mathrm{l}$ of $0 \cdot 2 \%$ acetic acid. Then, the retained molecules (flavanols and proanthocyanidins with a low grade of polymerisation and their metabolites) were eluted with $2 \times 50 \mu$ l of acetoneMilli-Q water-acetic acid solution (70:29·5:0.5, by vol.). The 
eluted solution was directly injected into the chromatographic system, and the sample volume was $2 \cdot 5 \mu \mathrm{l}$.

\section{Analysis of flavanols and proanthocyanidins with a} low grade of polymerisation and their metabolites by ultra-performance liquid chromatography-electrospray ionisation-MS/MS

Flavanols and proanthocyanidins with a low grade of polymerisation were analysed by Acquity ultra-performance-liquid chromatography from Waters and tandem MS, as reported in our previous studies ${ }^{(30,31)}$. Briefly, the column was Acquity high strength silica T3 $(100 \mathrm{~mm} \times 2.1 \mathrm{~mm}$ inner diameter, $1.8 \mu \mathrm{m}$ particle size) with $100 \%$ silica particles (Waters). The mobile phase was $0 \cdot 2 \%$ acetic acid as eluent A, and acetonitrile as eluent $\mathrm{B}$. The flow rate was $0.4 \mathrm{ml} / \mathrm{min}$ and the analysis time $12.5 \mathrm{~min}$. Tandem MS analyses were carried out on a triple quadrupole detector mass spectrometer (Waters) equipped with a Z-spray electrospray interface. The ionisation technique was electrospray ionisation. Flavanols and proanthocyanidins with a low grade of polymerisation and their metabolites were analysed in the negative ion mode and data were acquired through selected reaction monitoring.
For each analyte, two selected reaction monitoring transitions were studied, the most sensitive transition being selected for quantification and a second one for confirmation purposes (see the Supplementary material, available online). The dwell time established for each transition was $30 \mathrm{~ms}$. Data acquisition was carried out with MassLynx v 4.1 software (Waters). Considering the ultra-performance liquid chromatography elution order of catechin and epicatechin and the elution order of their metabolites, together with the MS fragmentation pattern, the earlier eluting peaks were assigned to catechin metabolites, while the peaks eluting later were assigned to epicatechin metabolites. Catechin and epicatechin metabolites were tentatively quantified using the calibration curve of $(+)$-catechin and (-)-epicatechin, respectively. Dimers, which corresponded to the sum of four peaks of the extracted ion chromatogram at the transition of $577>289^{(31)}$, were quantified using the calibration curve of the commercial standard

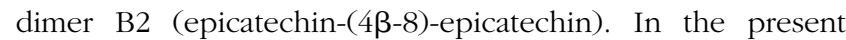
study, quality parameters of the method, such as the limit of detection (LOD) and the limit of quantification (LOQ), are reported. For the determination of catechin in the liver and adipose tissue, LOD were 0.4 and $1.8 \mathrm{nmol} / \mathrm{g}$, and LOQ were 1.0 and $6 \cdot 1 \mathrm{nmol} / \mathrm{g}$, respectively. On the other hand, for the determination of epicatechin in the liver and adipose tissue, LOD

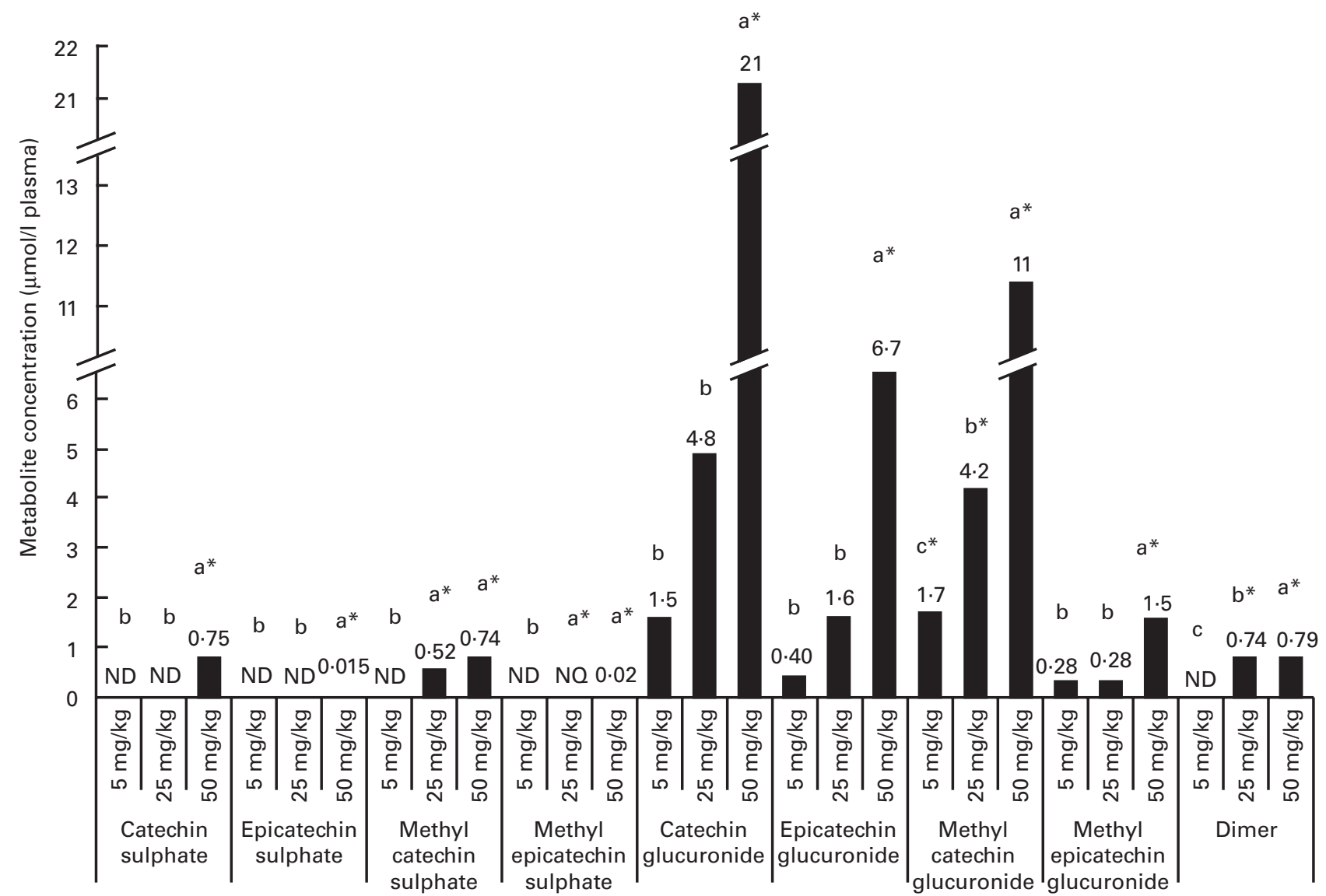

Fig. 1. Flavanol metabolites and procyanidins with a low grade of polymerisation concentrations, expressed as $\mu \mathrm{mol} / \mathrm{l}$, quantified in plasma after a $21 \mathrm{~d}$ long-term intake of grape seed proanthocyanidin extract (GSPE) at different doses (5, 25 and $50 \mathrm{mg} / \mathrm{kg}$ body weight). ${ }^{\text {a,b,c }}$ Mean values with unlike letters within the same metabolite concentration were significantly different between the GSPE doses $(P<0.05)$. ${ }^{*}$ Mean values were significantly different between the tested dose and the control group of rats (without GSPE intake) $(P<0.05)$. ND, not detected; NQ, not quantified. 
were 0.6 and $1.6 \mathrm{nmol} / \mathrm{g}$, and LOQ were 1.0 and $4.5 \mathrm{nmol} / \mathrm{g}$, respectively ${ }^{(29)}$. As a consequence, in the present study, when the concentration of the generated metabolite was lower than the LOD, it was considered not detected, and when its concentration was below the LOQ, it was considered not quantified.

\section{Statistical analysis}

Data are expressed as means and standard deviations. Statistical analysis was performed using two-way ANOVA followed by the Tukey-Kramer honestly significant difference multiple comparison test. A $P$ value $<0.05$ was considered as significant. All statistical analyses were performed using JMP software (version 8.0.2; SAS Institute, Inc.).

\section{Results}

After a regular $21 \mathrm{~d}$ consumption of GSPE at different doses (5, 25 and $50 \mathrm{mg} / \mathrm{kg}$ body weight), several flavanol metabolites were identified in the plasma (Fig. 1). Glucuronidated conjugates followed by methyl glucuronidated conjugates were the main flavanol metabolites quantified in the plasma, and methyl catechin sulphate was quantified at lower concentrations. In contrast, methyl epicatechin sulphate was only quantified at the trace level $(0.02 \mu \mathrm{mol} / 1$ plasma $)$ after the higher tested long-term dose $(50 \mathrm{mg} / \mathrm{kg})$. Additionally, dimer was also quantified in plasma samples. Significant differences $(P<0.05)$ were observed for flavanol plasma concentrations between the doses. For plasma glucuronidated forms, significant differences were only detected with the highest tested dose $\left(\mathrm{C}_{\text {Cat_50 mg } / \mathrm{kg}} 21 \mu \mathrm{mol} / 1\right.$ plasma and $\mathrm{C}_{\text {Epi__5 } \mathrm{mg} / \mathrm{kg}}$ $11 \mu \mathrm{mol} / 1$ for catechin glucuronide $(P<0 \cdot 001)$ and epicatechin glucuronide $(P<0.001)$, respectively) compared with the lowest doses, although glucuronidated forms of catechin and epicatechin were quantified in the plasma $21 \mathrm{~d}$ after all the tested long-term intakes. A similar behaviour, with significant differences at $50 \mathrm{mg} / \mathrm{kg}$, was observed for methyl epicatechin glucuronide. On the other hand, dimer was quantified at similar concentrations (approximately $0.75 \mu \mathrm{mol} / 1$ plasma) after the 25 and $50 \mathrm{mg} / \mathrm{kg}$ of long-term doses. However, dimer was not detected after the $5 \mathrm{mg} / \mathrm{kg}$ dose. Methyl catechin sulphate was quantified at a lower concentration in the plasma than glucuronide $(P<0.001)$ and methyl glucuronide $(P<0.001)$ conjugates after the 25 and $50 \mathrm{mg} / \mathrm{kg}$ long-term doses, and catechin sulphate was only quantified with the $50 \mathrm{mg} / \mathrm{kg}$ dose.

Related to the distribution of flavanol metabolites in tissues, as shown in Fig. 2, the liver and muscle showed a direct relationship between the accumulation and the administered doses of GSPE for all the quantified flavanol metabolites. No flavanol metabolites were quantified in the liver after the lower long-term dose $(5 \mathrm{mg} / \mathrm{kg})$. In addition, high concentration levels were detected at 25 and $50 \mathrm{mg} / \mathrm{kg}$. Methyl glucuronide conjugates were the most abundant flavanol metabolites quantified in the liver. Glucuronidated conjugates were the most abundant metabolites detected in the muscle, followed by methyl glucuronidated conjugates. As regards the adipose tissues (Fig. 3), a significant dose-dependent accumulation was observed in BAT for the total flavanol metabolites. Significant differences were detected for all the quantified metabolites $21 \mathrm{~d}$ after the $50 \mathrm{mg} / \mathrm{kg}$ dose compared with the lower doses $(P<0 \cdot 001)$. Glucuronidated and methyl glucuronidated conjugates of catechin and epicatechin were determined in BAT. On the other hand, in the mesenteric and perirenal adipose tissues, no dose-dependent accumulation was observed. Also glucuronidated and methyl glucuronidated conjugates of catechin and epicatechin were quantified in both adipose tissues. Nonetheless, with the $5 \mathrm{mg} / \mathrm{kg}$ dose, practically, no metabolites were detected and significant differences for epicatechin and catechin glucuronide were only detected in the brown and mesenteric adipose tissues $(P<0.05)$ between 25 and $50 \mathrm{mg} / \mathrm{kg}$. It should be noted that dimer was not detected in any of the studied tissues (data not shown).

Table 1 allows the detection of significant differences between the tissues for each metabolite differentiating between the ingested doses of GSPE. For catechin glucuronide, at the $5 \mathrm{mg} / \mathrm{kg}$ dose, muscle was the tissue with the greatest accumulation. In contrast, tissue distribution was more homogeneous at higher doses, with no significant differences between the muscle, BAT, mesenteric adipose tissue and perirenal adipose tissue, except for the liver, in which the concentration of metabolites remained low. The opposite situation was observed for methyl catechin glucuronide that at low dose $(5 \mathrm{mg} / \mathrm{kg})$ was not detected in any tissue. Nevertheless, with increasing doses, accumulation was concentrated in the liver. Regarding methyl sulphated conjugates, tissue deposition was very low. A low accumulation of metabolites after the treatment with doses of GSPE at 25 and $50 \mathrm{mg} / \mathrm{kg}$ was only observed in the liver. The epicatechin glucuronidated conjugate was accumulated mainly in the mesenteric adipose tissue during the $5 \mathrm{mg} / \mathrm{kg}$ dose. At 25 and $50 \mathrm{mg} / \mathrm{kg}$, accumulation was concentrated in the three adipose tissues (brown, perirenal and mesenteric) with no significant difference between them. Methyl epicatechin glucuronide, at the $5 \mathrm{mg} / \mathrm{kg}$ dose, was only accumulated in BAT, showing a value of concentration between the LOD $(1.8 \mathrm{nmol} / \mathrm{g}$ tissue) and the LOQ $(6 \cdot 1 \mathrm{nmol} / \mathrm{g}$ tissue $)$ determined for epicatechin in the adipose tissue ${ }^{(27)}$. At a higher dose of GSPE $(25 \mathrm{mg} / \mathrm{kg})$, mesenteric and perirenal adipose tissues showed the highest accumulations. In return, at $50 \mathrm{mg} / \mathrm{kg}$ of GSPE, liver, mesenteric and perirenal adipose tissues showed the highest concentration. No phenolic metabolites were detected in plasma and tissues in the control group of rats (data not shown).

\section{Discussion}

Liver, muscle and adipose tissues are crucial in the homeostasis of TAG and glucose. Moreover, obesity depends on fat accumulation in WAT and on energy wasted in BAT $^{(32)}$. Therefore, in order to understand the role of flavanols in improving hypertriacylglycerolaemia ${ }^{(13,14,33,34)}$, hyperglycaemia ${ }^{(4,35-38)}$ and obesity ${ }^{(11)}$, it is essential to know whether flavanols reach these organs and which metabolites could be responsible for their effects. The present study shows the plasma bioavailability and tissue distribution of flavanol metabolites in the WAT 
(A)

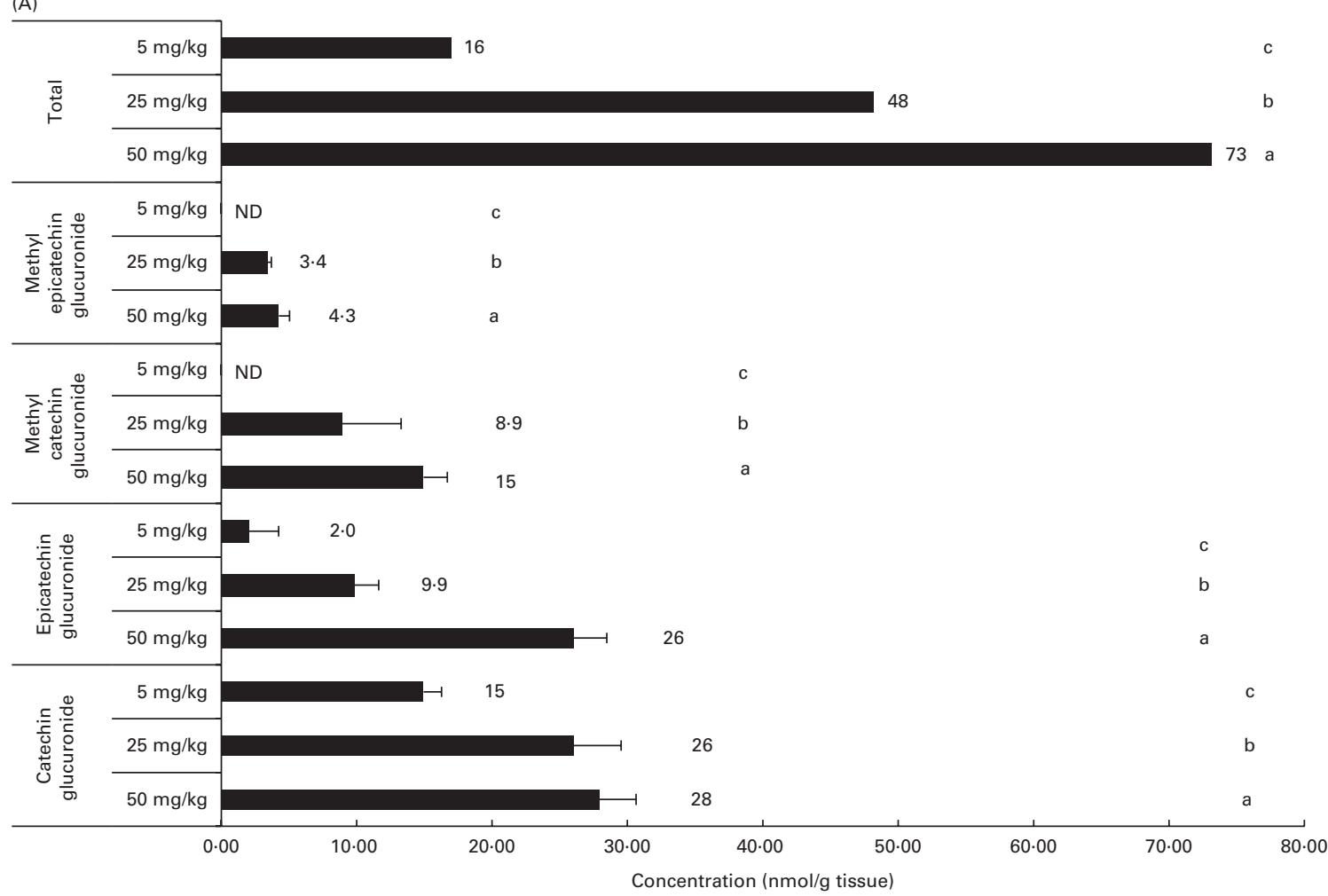

(B)

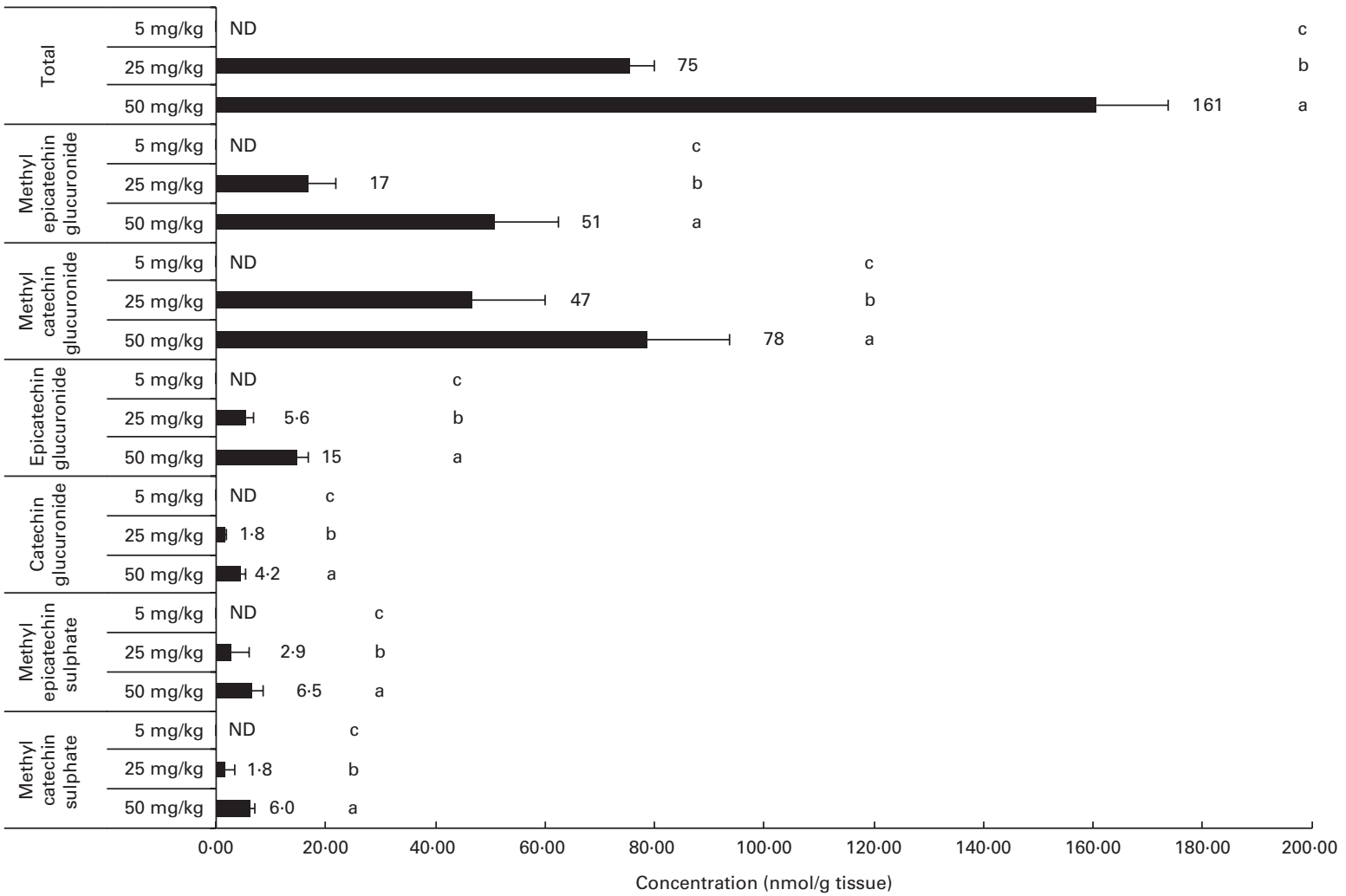

Fig. 2. Flavanol metabolites quantified in (A) muscle and (B) liver after a $21 \mathrm{~d}$ long-term intake of grape seed proanthocyanidin extract at different doses $(5$, 25 and $50 \mathrm{mg} / \mathrm{kg}$ body weight). Values are means (nmol/g tissue), with standard deviations represented by horizontal bars. ${ }^{a, b, c}$ Mean values with unlike letters within the same metabolite concentration were significantly different between the doses $(P<0.05)$. ND, not detected. 
(A)

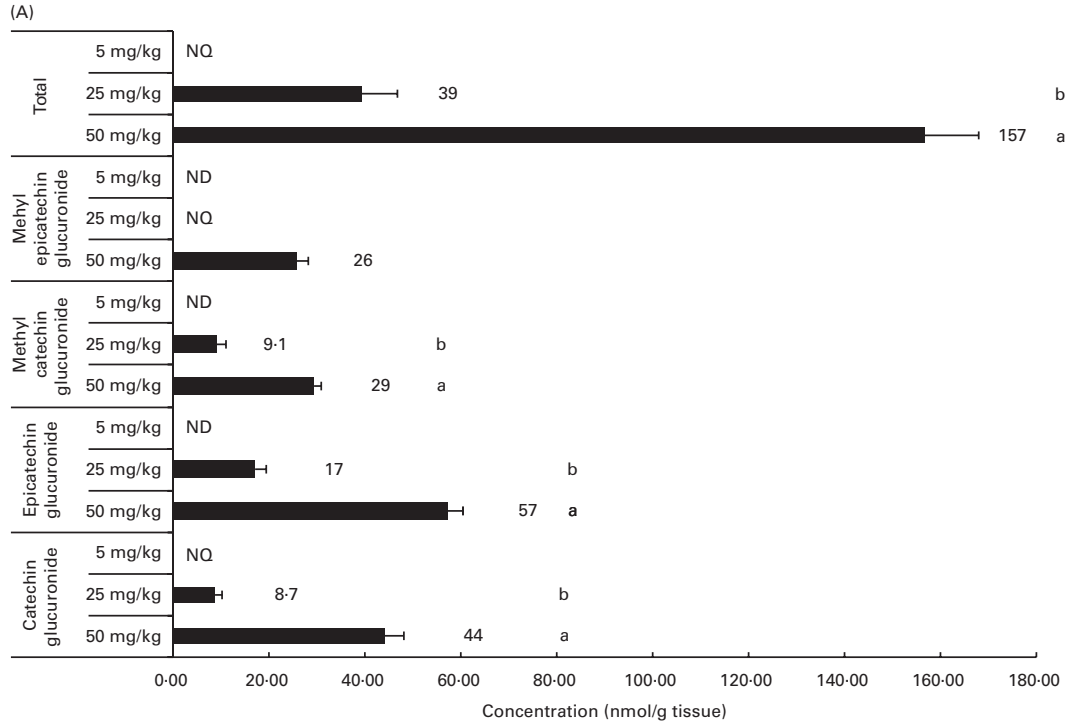

(B)

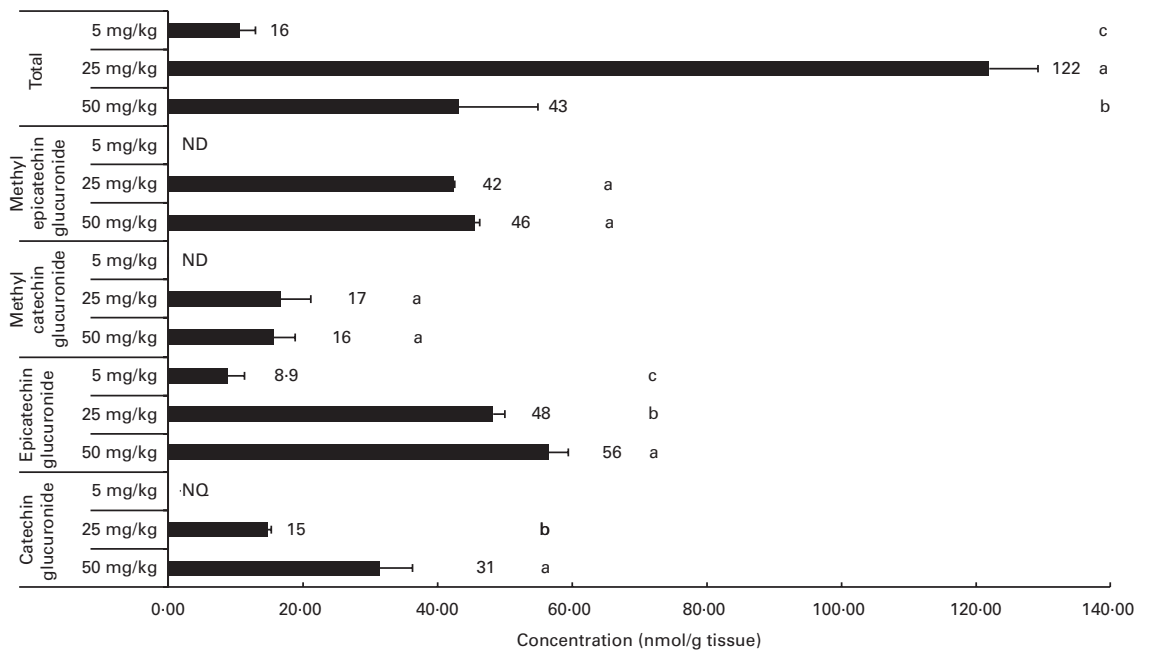

(C)

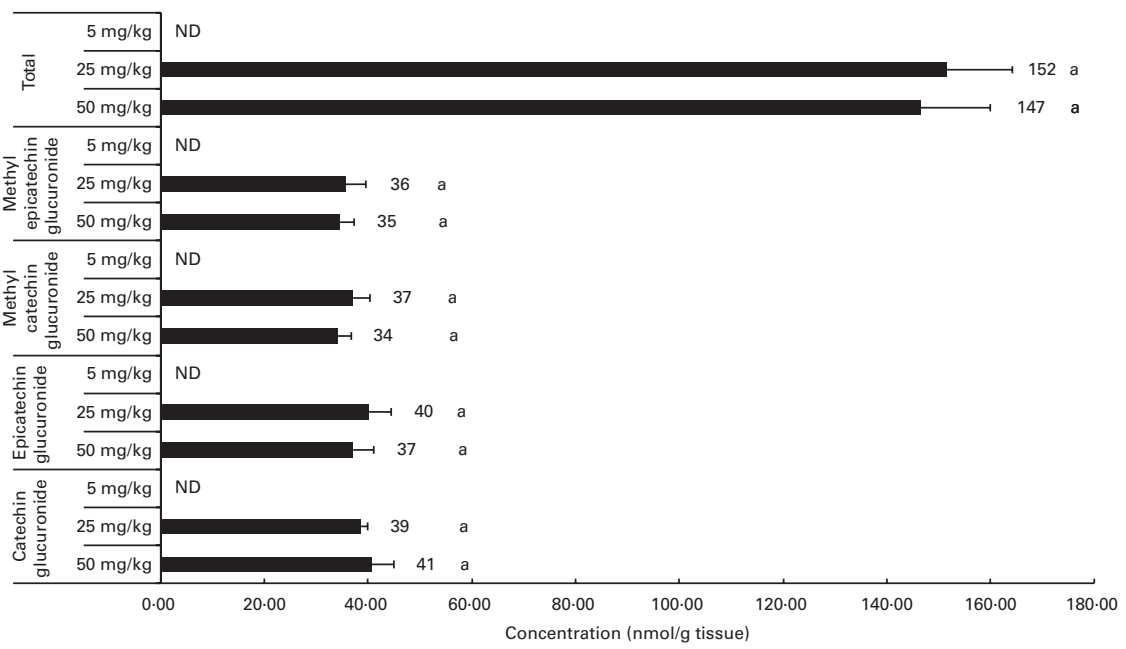

Fig. 3. Flavanol metabolites quantified in white adipose tissues (mesenteric (A) and perirenal (B)) and brown adipose tissues (C) after a $21 \mathrm{~d}$ long-term intake of grape seed proanthocyanidin extract at different doses $(5,25$ and $50 \mathrm{mg} / \mathrm{kg}$ body weight). Values are means (nmol/g tissue), with standard deviations represented by horizontal bars. ${ }^{\mathrm{a}, \mathrm{b}, \mathrm{c}}$ Mean values with unlike letters within the same metabolite concentration were significantly different between the doses $(P<0.05)$. ND, not detected; $N Q$, not quantified. 
(mesenteric and perirenal), BAT, muscle and liver after a regular $21 \mathrm{~d}$ intake of GSPE. The results obtained show that each of the organs studied has a specific pattern of metabolite accumulation and response to the assayed GSPE doses.

The presence of several catechin and epicatechin metabolites in the plasma reinforces the fact that procyanidins are intensely metabolised by the small intestine and liver. Plasma catechin conjugates are more abundant than epicatechin conjugates, a fact directly related to the proportion of catechin and epicatechin in GSPE (6.3 (SD 0.54) $\mu \mathrm{mol} / \mathrm{g}$ of GSPE and $2 \cdot 4(\mathrm{SD} 0 \cdot 13) \mu \mathrm{mol} / \mathrm{g}$ of GSPE, respectively, data shown in a previous work $\left.{ }^{(21)}\right)$. Glucuronidated conjugates, followed by methyl glucuronidated conjugates, were the main flavanol metabolites detected in the plasma, and this agrees with the existing literature ${ }^{(27,39-42)}$.

Previous studies have shown a high number of phase II metabolites in the liver after a long-term intake of catechin ${ }^{(43)}$. By contrast, after an acute intake of a proanthocyanidin-rich extract, these phenolic metabolites were not detected in the liver ${ }^{(27)}$. However, the results of the present study show that the sulphate conjugates of catechin and epicatechin were only deposited in the liver, showing a dose-response accumulation and indicating

Table 1. Flavanol metabolite concentrations in the rat liver, muscle, brown adipose tissue and white adipose tissues (mesenteric and perirenal) after a $21 \mathrm{~d}$ chronic intake of grape seed proanthocyanidin extract at different doses $(5,25$ and $50 \mathrm{mg} / \mathrm{kg}$ body weight), with $n 5$ for each dose

(Mean values ( $\mathrm{nmol} / \mathrm{g}$ tissues) and standard deviations)

\begin{tabular}{|c|c|c|c|c|c|c|}
\hline \multirow[b]{3}{*}{ Tissue } & \multicolumn{6}{|c|}{ Ingested dose } \\
\hline & \multicolumn{2}{|c|}{$50 \mathrm{mg} / \mathrm{kg}$} & \multicolumn{2}{|c|}{$25 \mathrm{mg} / \mathrm{kg}$} & \multicolumn{2}{|c|}{$5 \mathrm{mg} / \mathrm{kg}$} \\
\hline & Mean & SD & Mean & SD & Mean & SD \\
\hline \multicolumn{7}{|l|}{ Catechin glucuronide } \\
\hline Liver & $4 \cdot 2^{b}$ & $1 \cdot 1$ & $1 \cdot 8^{\mathrm{C}}$ & 0.07 & \multicolumn{2}{|c|}{ ND } \\
\hline Muscle & $28^{a}$ & $2 \cdot 6$ & $26^{a, b}$ & 3.5 & 15 & 1.4 \\
\hline Brown adipose tissue & $44^{\mathrm{a}}$ & 3.9 & $8 \cdot 7^{\mathrm{b}, \mathrm{c}}$ & 1.6 & & \\
\hline Mesenteric adipose tissue & $31^{a}$ & 4.9 & $15^{\mathrm{b}, \mathrm{c}}$ & 0.75 & & \\
\hline Perirenal adipose tissue & $41^{\mathrm{a}}$ & $4 \cdot 2$ & $39^{a}$ & 1.3 & & \\
\hline$P$ & \multicolumn{2}{|c|}{$<0.0001$} & \multicolumn{2}{|c|}{$<0.0001$} & & \\
\hline \multicolumn{7}{|l|}{ Methyl catechin glucuronide } \\
\hline Liver & $78^{a}$ & $15 \cdot 2$ & $47^{a}$ & 13 & & \\
\hline Muscle & $15^{\mathrm{b}}$ & $1 \cdot 2$ & $8 \cdot 9^{b}$ & 4.4 & & \\
\hline Brown adipose tissue & $29^{b}$ & $1 \cdot 7$ & $9 \cdot 1^{\mathrm{b}}$ & 1.9 & & \\
\hline Mesenteric adipose tissue & $16^{b}$ & $3 \cdot 2$ & $17^{\mathrm{a}, \mathrm{b}}$ & $4 \cdot 3$ & & \\
\hline Perirenal adipose tissue & $34^{b}$ & $2 \cdot 7$ & $37^{\mathrm{a}, \mathrm{b}}$ & $3 \cdot 2$ & & \\
\hline$P$ & \multicolumn{2}{|c|}{$<0.0001$} & \multicolumn{2}{|c|}{0.0048} & \multicolumn{2}{|c|}{-} \\
\hline \multicolumn{7}{|l|}{ Methyl catechin sulphate } \\
\hline Liver & $6 \cdot 0$ & 0.98 & $1 \cdot 8$ & $1 \cdot 6$ & & \\
\hline Muscle & \multicolumn{2}{|c|}{ ND } & \multicolumn{2}{|c|}{ ND } & \multicolumn{2}{|c|}{ ND } \\
\hline Brown adipose tissue & \multicolumn{2}{|c|}{ ND } & \multicolumn{2}{|c|}{ ND } & \multicolumn{2}{|c|}{ ND } \\
\hline Mesenteric adipose tissue & \multicolumn{2}{|c|}{ ND } & \multicolumn{2}{|c|}{ ND } & \multicolumn{2}{|c|}{ ND } \\
\hline Perirenal adipose tissue & & & & & & \\
\hline$P$ & $<0$ & 01 & & & & \\
\hline Epicatechin glucuronide & & & & & & \\
\hline Liver & $15^{b}$ & $2 \cdot 1$ & $5 \cdot 6^{c}$ & $1 \cdot 3$ & & \\
\hline Muscle & $26^{b}$ & 2.4 & $9 \cdot 9^{\mathrm{b}, \mathrm{c}}$ & $1 \cdot 7$ & $2 \cdot 0^{\mathrm{b}}$ & $0 \cdot 1$ \\
\hline Brown adipose tissue & $57^{a}$ & $3 \cdot 1$ & $17^{\mathrm{b}}$ & $2 \cdot 2$ & & \\
\hline Mesenteric adipose tissue & $56^{\mathrm{a}}$ & 2.9 & $48^{a}$ & $1 \cdot 7$ & $8 \cdot 9^{a}$ & $2 \cdot 3$ \\
\hline Perirenal adipose tissue & $37^{a, b}$ & $3 \cdot 8$ & $40^{a}$ & $4 \cdot 2$ & & \\
\hline$P$ & $<$ & 01 & $<0$ & 01 & $<0$ & 01 \\
\hline Methyl epicatechin glucuronide & & & & & & \\
\hline Liver & $51^{\mathrm{a}}$ & 11 & $17^{\mathrm{b}}$ & 4.9 & & \\
\hline Muscle & $4 \cdot 3^{c}$ & 0.7 & $3 \cdot 4^{\mathrm{c}}$ & 0.3 & & \\
\hline Brown adipose tissue & $26^{b}$ & 2.4 & & & & \\
\hline Mesenteric adipose tissue & $46^{\mathrm{a}}$ & 0.69 & $42^{\mathrm{a}}$ & 0.34 & & \\
\hline Perirenal adipose tissue & $35^{a, b}$ & $2 \cdot 7$ & $36^{a}$ & 3.9 & & \\
\hline$P$ & $<$ & 01 & $<0$ & & & \\
\hline Methyl epicatechin sulphate & & & & & & \\
\hline Liver & $6 \cdot 5$ & $1 \cdot 2$ & 2.9 & $0 \cdot 15$ & & \\
\hline Muscle & & & & & & \\
\hline Brown adipose tissue & & & & & & \\
\hline Mesenteric adipose tissue & & & & & & \\
\hline Perirenal adipose tissue & & & & & & \\
\hline$P$ & & & & & & \\
\hline
\end{tabular}


sulphation capacity of rat hepatocytes. Nonetheless, these sulphated conjugates were not detected in the liver after the treatment with $5 \mathrm{mg}$ GSPE/kg body weight. Moreover, their presence in the plasma at low concentrations could reflect the possible sulphotransferase activity of the platelets, as was observed by Anderson et al. ${ }^{(44)}$ who incubated hydroxytyrosol, a phenyl alcohol typical of virgin olive oil, in whole blood.

Glucuronide conjugates were detected in all the organs studied, but their distribution and concentration may depend on methylation. Non-methylated glucuronide derivatives were mainly accumulated in BAT and in the two white adipose depots studied, mesenteric and perirenal. On the other hand, methyl catechin glucuronide was accumulated mainly in the liver, whereas methyl epicatechin glucuronide was accumulated mainly in BAT and WAT. It is important to highlight that the accumulation of glucuronide derivatives in white adipose depots was not dose responsive. In both the WAT studied (perirenal and mesenteric), the levels of glucuronide derivatives were similar, at 25 and $50 \mathrm{mg}$ of GSPE/ $\mathrm{kg}$ body weight. This could be related to the storage limit in white adipose cells. However, this might be more related to the saturation of uridine 5'-diphospho-glucuronosyltransferase enzymes responsible for the formation of glucuronidated conjugates. These enzymes are located in the endoplasmic reticulum in many tissues and catalyse the transfer of glucuronic acid from uridine 5'-diphospho-glucuronic acid to steroids, bile acids, polyphenols and xenobiotics ${ }^{(45)}$. Moreover, the concentration of some of these metabolites was even higher than that in the other tissues studied. Taken together, it can be suggested that visceral WAT could be a store for flavanol metabolites in the body. Nonetheless, further studies are needed to understand whether flavanols accumulate in adipocytes or other cell types in the adipose tissue.

BAT could represent a very important target for flavanol metabolites, due to, for example, their improvement in mitochondrial function related to energy homeostasis of the $\mathrm{BAT}^{(17)}$. This tissue is the only tissue with detectable levels of all the glucuronidated derivatives at the lowest GSPE dose ( $5 \mathrm{mg} / \mathrm{kg}$ body weight). Moreover, BAT showed a dose-response in the concentration of all the conjugate metabolites of catechin and epicatechin. Moreover, some of these metabolites reached high concentrations, probably related to the high irrigation of this type of adipose tissue by blood vessels ${ }^{(46)}$. These results, together with the possible enhancement of thermogenic capacity and the improvement in mitochondrial function exerted by a long-term supplementation of proanthocyanidins in $\mathrm{BAT}^{(17,47)}$, it can be suggested that proanthocyanidins may play an important role in reducing or preventing obesity by modulating the functionality of BAT at low doses.

The dose-dependent disposition of phase II metabolites of procyanidins detected in the muscle may also be related to an improvement in mitochondrial function in skeletal muscle detected in a previous experiment ${ }^{(47)}$, suggesting an improvement in the activity of enzymes involved in the oxidation and metabolism of pyruvate, and a shift in priority to glycosidic metabolism rather than lipid metabolism.

\section{Conclusions}

In the present study, after a long-term intake of flavanol-rich extract at different doses, plasma bioavailability, distribution and accumulation of flavanols and their metabolites in the adipose tissues, muscle and liver were studied. Each of the studied organs has a specific behaviour of accumulation and response to the assayed GSPE doses, with a clear doseresponse in BAT, in which flavanols could play an important role in reducing or preventing obesity by modulating the functionality of that tissue. The results of the present experiment could be useful for future in vitro research with adipose cell culture giving information about the physiological concentrations reached in specific adipose tissues after a long-term intake of flavanols.

\section{Supplementary material}

To view supplementary material for this article, please visit http://dx.doi.org/10.1017/S0007114513000706

\section{Acknowledgements}

The present study was supported by grant no. AGL 200800387/ALI and AGL2009-13517-C03-02 from the Spanish Government. It was also supported by the Catalan Government (Interdepartmental Commission for Research and Technological Innovation) through the A. Serra grant. The authors' contributions are as follows: M.-J. M., L. A. and C. B. had full access to all of the data in the study and took responsibility for the integrity of the data and the accuracy of the data analysis; M.-J. M., L. A. and C. B. contributed to the study concept and design; A. S. and A. M. were responsible for the acquisition of the data on grape seed procyanidin extract; L. A. and C. B. were involved in the treatment of the animals and plasma and tissue collection; A. S., A. M. and M.-J. M. were responsible for the acquisition of the data on procyanidin metabolites in plasma and tissues; A. S., A. M., M.-J. M., C. B. and L. A. conducted the analyses and interpreted the data; A. S., M.-J. M., L. A. and C. B. drafted the manuscript; A. S., A. M., M.-J. M., L. A. and C. B. critically revised the manuscript for important intellectual content; A. M. and C. B. provided administrative, technical and logistic support. The authors declare that there is no conflict of interest.

\section{References}

1. Zamora-Ros R, Andres-Lacueva C, Lamuela-Raventós RM, et al. (2010) Estimation of dietary sources and flavonoid intake in a Spanish adult population (EPIC-Spain). $J \mathrm{Am}$ Diet Assoc 110, 390-398.

2. Zamora-Ros R, Knaze V, Luján-Barroso L, et al. (2013) Differences in dietary intakes, food sources and determinants of total flavonoids between Mediterranean and non-Mediterranean countries participating in the European Prospective Investigation into Cancer and Nutrition (EPIC) study. $\mathrm{Br} \mathrm{J}$ Nutr 109, 1498-1507.

3. Wang Y, Chung S, Song WO, et al. (2011) Estimation of daily proanthocyanidin intake and major food sources in the U.S. diet. J Nutr 141, 447-452. 
4. Grassi D, Desideri G, Necozione S, et al. (2008) Blood pressure is reduced and insulin sensitivity increased in glucoseintolerant, hypertensive subjects after 15 days of consuming high-polyphenol dark chocolate. J Nutr 138, 1671-1676.

5. Schroeter H, Heiss C, Spencer JPE, et al. (2010) Recommending flavanols and procyanidins for cardiovascular health: current knowledge and future needs. Mol Asp Med 31, 546-557.

6. McCullough ML, Peterson JJ, Patel R, et al. (2012) Flavonoid intake and cardiovascular disease mortality in a prospective cohort of US adults. Am J Clin Nutr 95, 454-464.

7. Cutler GJ, Nettleton JA, Ross JA, et al. (2008) Dietary flavonoid intake and risk of cancer in postmenopausal women: the Iowa Women's Health Study. Int J Cancer 123, 664-671.

8. Mellor DD, Sathyapalan T, Kilpatrick ES, et al. (2010) Highcocoa polyphenol-rich chocolate improves HDL cholesterol in type 2 diabetes patients. Diabet Med 27, 1318-1321.

9. Bladé C, Arola L \& Salvadó MJ (2010) Hypolipidemic effects of proanthocyanidins and their underlying biochemical and molecular mechanisms. Mol Nutr Food Res 54, 37-59.

10. Hooper L, Kay C, Abdelhamid A, et al. (2012) Effects of chocolate, cocoa, and flavan-3-ols on cardiovascular health: a systematic review and meta-analysis of randomized trials. Am J Clin Nutr 95, 740-751.

11. Basu A, Sanchez K, Leyva MJ, et al. (2010) Green tea supplementation affects body weight, lipids, and lipid peroxidation in obese subjects with metabolic syndrome. $J \mathrm{Am}$ Coll Nutr 29, 31-40.

12. Del Bas JM, Fernández-Larrea J, Blay M, et al. (2005) Grape seed procyanidins improve atherosclerotic risk index and induce liver CYP7A1 and SHP expression in healthy rats. FASEB J 19, 479-481.

13. Quesada H, Díaz S, Pajuelo D, et al. (2012) The lipidlowering effect of dietary proanthocyanidins in rat involves both chylomicron-rich and VLDL-rich fractions. Br J Nutr 108, 208-217.

14. Quesada H, Del Bas JM, Pajuelo D, et al. (2009) Grape seed proanthocyanidins correct dyslipidemia associated with a high-fat diet in rats and repress genes controlling lipogenesis and VLDL assembling in liver. Int J Obes 33, 1007-1012.

15. Pinent M, Blay M, Bladé MC, et al. (2004) Grape seedderived procyanidins have an antihyperglycemic effect in streptozotocin-induced diabetic rats and insulinomimetic activity in insulin-sensitive cell lines. Endocrinology $\mathbf{1 4 5}$, 4985-4990.

16. Pinent M, Cedó L, Montagut G, et al. (2012) Procyanidins improve some disrupted glucose homoeostatic situations: an analysis of doses and treatments according to different animal models. Critical Rev Food Sci Nutr 52, 569-584.

17. Pajuelo D, Díaz S, Quesada H, et al. (2011) Acute administration of grape seed proanthocyanidin extract modulates energetic metabolism in skeletal muscle and BAT mitochondria. J Agric Food Chem 59, 4279-4287.

18. Montagut G, Onnockx S, Vaqué M, et al. (2010) Oligomers of grape-seed procyanidin extract activate the insulin receptor and key targets of the insulin signaling pathway differently from insulin. $J$ Nutr Biochem 21, 476-481.

19. Del Bas JM, Ricketts ML, Baiges I, et al. (2008) Dietary procyanidins lower triglyceride levels signaling through the nuclear receptor small heterodimer partner. Mol Nutr Food Res 52, 1172-1181.

20. Del Bas JM, Ricketts ML, Vaqué M, et al. (2009) Dietary procyanidins enhance transcriptional activity of bile acidactivated FXR in vitro and reduce triglyceridemia in vivo in a FXR-dependent manner. Mol Nutr Food Res 53, 805-814.
21. Serra A, Macià A, Romero MP, et al. (2010) Bioavailability of procyanidin dimers and trimers and matrix food effects in in vitro and in vivo models. Br J Nutr 103, 944-952.

22. Baba S, Osakabe N, Natsume M, et al. (2002) Absorption and urinary excretion of procyanidin B2 [epicatechin-(4b-8)epicatechin] in rats. Free Radic Biol Med 33, 142-148.

23. Holt RR, Lazarus SA, Cameron Sullards M, et al. (2002) Procyanidin dimer B2 [epicatechin-(4b-8)-epicatechin] in human plasma after the consumption of a flavanol-rich cocoa. Am J Clin Nutr 76, 798-804.

24. Zhu QY, Holt RR, Lazarus SA, et al. (2002) Stability of the flavan-3-ols epicatechin and catechin and related dimeric procyanidins derived from cocoa. J Agric Food Chem 50 1700-1705.

25. Okushio K, Suzuki M, Matsumoto N, et al. (1999) Identification of (-)-epicatechin metabolites and their metabolic fate in the rat. Drug Metab Dispos 27, 309-316.

26. Natsume M, Osakabe N, Oyama M, et al. (2003) Structures of $(-)$-epicatechin glucuronide identified from plasma and urine after oral ingestion of (-)-epicatechin: differences between human and rat. Free Radic Biol Med 34, 840-849.

27. Serra A, Macià A, Romero MP, et al. (2011) Distribution of procyanidins and their metabolites in rat plasma and tissues after an acute intake of hazelnut extract. Food Funct 2, $562-568$.

28. Serra A, Macià A, Rubió L, et al. (2012) Distribution of procyanidins and their metabolites in rat plasma and tissues in relation to ingestion of procyanidin-enriched or procyanidin-rich cocoa creams. Eur J Nutr (Epublication ahead of print version 11 July 2012).

29. Serra A, Macià A, Romero MP, et al. (2011) Rapid methods to determine procyanidins, anthocyanins, theobromine and caffeine in rat tissues by liquid chromatography-tandem mass spectrometry. J Chromatogr B 879, 1519-1528.

30. Martí MP, Pantaleón A, Rozek A, et al. (2010) Rapid analysis of procyanidins and anthocyanins in plasma by microelution SPE and ultra-HPLC. $J$ Sep Sci 33, 2841-2853.

31. Serra A, Macià A, Romero MP, et al. (2009) Determination of procyanidins and their metabolites in plasma samples by improved liquid chromatography-tandem mass spectrometry. J Chromatogr B 877, 1169-1176.

32. Cinti S (2012) The adipose organ at a glance. Dis Models Mech 5, 588-594.

33. Ruzaidi A, Amin I, Nawalyah AG, et al. (2005) The effect of Malaysian cocoa extract on glucose levels and lipid profiles in diabetic rats. J Ethnopharmacol 98, 55-60.

34. Ruzaidi AMM, Abbe MMJ, Amin I, et al. (2008) Protective effect of polyphenol-rich extract prepared from Malaysian cocoa (Theobroma cacao) on glucose levels and lipid profiles in streptozotocin-induced diabetic rats. J Sci Food Agric 88, 1442-1447.

35. Landrault N, Poucheret P, Azay J, et al. (2003) Effect of a polyphenols-enriched chardonnay white wine in diabetic rats. J Agric Food Chem 51, 311-318.

36. Maritim A, Dene BA, Sanders RA, et al. (2003) Effects of pycnogenol treatment on oxidative stress in streptozotocininduced diabetic rats. J Biochem Mol Toxicol 17, 193-199.

37. Ceriello A, Bortolotti N, Motz E, et al. (2001) Red wine protects diabetic patients from meal-induced oxidative stress and thrombosis activation: a pleasant approach to the prevention of cardiovascular disease in diabetes. Eur J Clin Invest 31, 322-328.

38. Caimi G, Carollo C \& Lo Presti R (2003) Diabetes mellitus: oxidative stress and wine. Curr Med Res Opin 19, 581-586.

39. Ottaviani JI, Momma TY, Kuhnle GK, et al. (2012) Structurally related (-)-epicatechin metabolites in humans: 
assessment using de novo chemically synthesized authentic standards. Free Radic Biol Med 52, 1403-1412.

40. Abd El Mohsen MM, Kuhnle G, Rechner AR, et al. (2002) Uptake and metabolism of epicatechin and its access to the brain after oral ingestion. Free Radic Biol Med 33, 1693-1702.

41. Harada M, Kan Y, Naoki H, et al. (1999) Identification of the major antioxidative metabolites in biological fluids of the rat with ingested (+)-catechin and (-)-epicatechin. Biosci Biotechnol Biochem 63, 973-977.

42. Tsang C, Auger C, Mullen W, et al. (2005) The absorption, metabolism and excretion of flavan-3-ols and procyanidins following the ingestion of a grape seed extract by rats. $\mathrm{Br} \mathrm{J}$ Nutr 94, 170-181.

43. Urpi-Sarda M, Ramiro-Puig E, Khan N, et al. (2010) Distribution of epicatechin metabolites in lymphoid tissues and testes of young rats with a cocoa-enriched diet. $\mathrm{Br} J$ Nutr 103, 1393-1397.

44. Anderson RJ, Garcia MJ, Liebentritt DK, et al. (1991) Localization of human blood phenol sulfotransferase activities: novel detection of the thermostable enzyme in granulocytes. J Lab Clin Med 118, 500-509.

45. Manach C, Scalbert A, Morand C, et al. (2004) Polyphenols: food sources and bioavailability. Am J Clin Nutr 79, $727-747$.

46. Ravussin E \& Galgani JE (2011) The implication of brown adipose tissue for humans. Annu Rev Nutr 31, 33-47.

47. Pajuelo D, Quesada H, Díaz S, et al. (2012) Chronic dietary supplementation of proanthocyanidins corrects the mitochondrial dysfunction of brown adipose tissue caused by diet-induced obesity in Wistar rats. Br J Nutr 107, 170-178. 